\title{
Investigation the distributions and pharmacokinetics of five Rhubarb anthraquinones in rabbits and rats
}

\begin{abstract}
The main effective components of Rhubarb are anthraquinones (AQs), most of which are glycoside and others are free. The concentrations of AQs derivatives (rhein, aloe-emodin, emodin and chrysophanol) in plasma and homogenate were assayed with a high performance liquid chromatography (HPLC) method. The pharmacokinetic parameter and distributions of rhubarb AQs in rabbits or rats were obtained after given different formulas respectively. The elimination of AQs was fit to a two-compartment model in rats and rabbits. There were no significant differences in the main pharmacokinetic parameters between with rhein and AQs in rats. AQs were distributed in kidney, liver, blood, heart progressively. The AQs were mainly existed as rhein in vivo and excreted by kidney. To the formulas containing rhubarb, rhein could be used as a probe for pharmacokinetic study of Rhubarb AQs in vivo.
\end{abstract}

Volume 3 Issue 2 - 2016

\author{
Ting Cui, Qi Xin Zhou, Dan Zhang, Xin Hui \\ Jiang
}

School of Pharmacy, Chongqing Medical University, China

Correspondence: Xin-Hui Jiang, Professor, School of Pharmacy, Chongqing Medical University, No. I Yixueyuan Road, Chongqing, 4000 16, People's Republic of China, Tel -68485098, Fax -68485098, Email jiangxinhu@hotmail.com

Received: July 12, 2016 | Published: September 19, 2016

Keywords: rhubarb, anthraquinones, pharmacokinetics, distribution, chrysophanol, aloeemodin, in vivo

\section{Introduction}

Rhubarb (Dahuang in Chinese), a well-known chinese herbal medicine, has long been used in the world and is officially listed in Chinese Pharmacopoeia which containing three species, Rheum palmatum L., Rheum officinale Bail and Rheum tanguticum Maxim. ex Balf. ${ }^{1}$ It is also formally listed in European and Japanese Pharmacopoeia. ${ }^{2,3}$ This important herbal medicine has been discerned for centuries in traditional medicine for its multiple pharmacological actions include antibacterial, laxative, antispasmodic and hemostatic., The main effective components of Rhubarb are five anthraquinones, namely rhein, emodin, aloe-emodin, chrysophanol and physcion. Most of which are glycoside. More than 16 pure compounds which about 3-5\% constituents of Rhubarb have been separated. These are the basis for the quality control of rhubarb and other plant drugs from Rheum, Cassia and Polygonum genera. The chemical structures of these AQs and internal standard (IS) are shown in Figure 1. We designed the experiment for tentative discussing the pharmacokinetic parameters and the excretion of Rhubarb AQs in vivo.<smiles>[R]c1cc(O)c2c(c1)C(=O)c1cc([R])cc(O)c1C2=O</smiles>

Internal stand
Chrysophanol
Physcion
Aloe-Emodinn
Rhein
Emodin

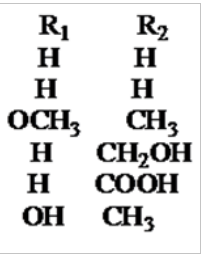

Figure I The chemical structures of rhein, aloe-emodin, emodin, internal standard, chrysophanol and physcion.

The methods commonly used for the separation and determination of all or some of the five major AQs in rhubarb are micellar electrokinetic chromatography (MEC), ${ }^{6,7}$ capillary zone electrophoresis ${ }^{8}$ and high performance liquid chromatography (HPLC). ${ }^{9-18}$

In our studies, we established a reliable and rapid method for simultaneous assay of five AQs in rhubarb on plasma and tissue homogenate and its related preparations using HPLC. Because of its sensitivity and speediness, HPLC is obtaining considerable attention in recent years for pharmaceutical and biomedical analysis. The results of our studies provided a reference for investigation of pharmacokinetics and distributions and of relations between pharmacokinetics, distributions and clinical efficacy of Rhubarb anthraquinones in human body.

\section{Materials and methods}

\section{Materials}

Rhein, Aloe-emodin, Emodin, Chrysophanol and physcion were obtained from the national institutes for food and drug control, 1,8-dihydroxyan-thraquinone (internal standard, IS), acetonitrile, methanol, phosphoric acid, sulfuric acid, and ethyl ester were of analytical grade.

\section{Subjects}

6 healthy rabbits, males, weight $2.0 \mathrm{~kg}-3.0 \mathrm{~kg}$, and 30 male and 30 female SD rats, weight $150 \mathrm{~g}-200 \mathrm{~g}$ were purchased from School of Pharmacy, Chongqing Medical University, and R.P China. They were individually housed in stainless steel cages and acclimatized for 3 days prior to experiments which were kept on a $12 \mathrm{~h}$ light /dark cycle, allowed free access to water prior to oral gavage and without drinking during the experiment.

\section{Method of oral gavage administration}

WPY granule formula composed of Rhubarb, Ginseng, Betel nuts and Pharbitic was a novel drug which was used to treat acute pancreatitis. The particles contain Aloe-emodin $7.9824 \mathrm{mg} / \mathrm{g}$, rhein $12.2679 \mathrm{mg} / \mathrm{g}$, Emodin $7.3886 \mathrm{mg} / \mathrm{g}$, Chrysophanol 9.4768mg/g and Physcion $6.3278 \mathrm{mg} / \mathrm{g}$. The WPY dried powder was adjusted with water to equivalent as $0.763 \mathrm{~g}$ original rhubarb herbs including rhein $4.50 \mathrm{mg} / \mathrm{mL}$. Preserved in refrigerator for rabbit and rats oral gavage.

The extract solution of Rhubarb was prepared as follow: Rhubarb was extracted twice with $70 \%$ ethanol, filtrated; the filtrate was concentrated to the relative density of 1.05 to 1.10 . Which contained Aloe-emodin $4.0097 \mathrm{mg} / \mathrm{g}$, rhein $11.8765 \mathrm{mg} / \mathrm{g}$, Emodin $3.7676 \mathrm{mg} / \mathrm{g}$, Chrysophanol $3.3462 \mathrm{mg} / \mathrm{g}$ and Physcion $2.3001 \mathrm{mg} / \mathrm{g}$ ? The liquid extract solution was adjusted to equivalent as $0.833 \mathrm{~g}$ of native herbs including rhein $4.51 \mathrm{mg} / \mathrm{mL}$. Preserved in refrigerator for rabbits and rats oral gavage. 
6 Healthy rabbits and 60 healthy SD rats were divided randomly into two groups, respectively. Blood was gotten and preserved in a tube which had added sodium heparin after rabbits had oral gavage of the extract solution of Rhubarb and the compounding formula solution of WPY respectively. Plasma and heart, liver and kidney tissues samples were preserved in refrigeration at $-20^{\circ} \mathrm{C}$ till analysis within two weeks.

\section{Preparation for plasma and tissues samples}

Each biological sample was added $100 \mathrm{~mL}$ internal standard solution and $1.0 \mathrm{~mL}$ of $15 \%$ sulfuric acid and mixed. First, the samples were placed in $70 \pm 2^{\circ} \mathrm{C}$ water bath for $30 \mathrm{~min}$ to hydrolysis conjunctive anthraquinones. Then, the samples were added $5.0 \mathrm{~mL}$ ethyl ether to extract Rhubarb anthraquinones, after vigorous vortexing $3 \mathrm{~min}$, the samples were centrifuged at $10,000 \times \mathrm{g}$ for $10 \mathrm{~min}$ at $-4^{\circ} \mathrm{C}$, the supernatant was drawn and dried with nitrogen at $40^{\circ} \mathrm{C}$. Finally, the clear supernatant was reconstituted with $100 \mathrm{~mL}$ mobile phase and $50 \mathrm{~mL}$ supernatant was injected into the HPLC instruments.

\section{Analytical method}

The analytical method was established as follow: HPLC instrument with a UV detector (Shimadzu LC-2010) and Hypersil C18 column (250mm'4.6mm i.d. Dalian Elite Analytical Instruments Co., Ltd. China) were used for analysis. The mobile phase components were methanol- acetonitrile-water (10:50:40, v: v: v, adjusted to $\mathrm{pH} 2.8$ with phosphoric acid), the detective wavelength was $225 \mathrm{~nm}$. The flow-rate was $1.0 \mathrm{~mL} / \mathrm{min}$. Plasma and homogenate concentrations of anthraquinones were measured by using the established method. The ratios of peak areas of aloe-emodin, rhein, emodin and chrysophanol to I.S. were plotted versus the concentrations of aloe-emodin, rhein, emodin and chrysophanol.

\section{Statistical and Pharmacokinetic analysis}

The pharmacokinetic parameters in rabbits and rats, intergroup comparison were calculated by DAS version 2.0 which bought from the Center for Drug Clinical Evaluation of Anhui Medical University, China. Statistical analysis was performed with the two-sided t-test and paired samples test. As the plasma pharmacokinetic parameter of rhein after oral gavage displayed a typical bi-exponential decline, the plasma concentration-time data was fitted into the classical twocompartment first-order open model $\left(\mathrm{C}=\mathrm{Ae}^{-\alpha t}+\mathrm{Be}^{-\beta t}\right)$. The plasma exposure (area under the plasma tetrandrine concentration-time curve $\left(\mathrm{AUC}_{0 \rightarrow 24 \mathrm{~h}}\right)$, clearance $\left(\mathrm{Cl}_{0 \rightarrow 24 \mathrm{~h}}\right)$, mean transit time $\left(\mathrm{MTT}_{0-24 \mathrm{~h}}\right)$ and terminal elimination half-life $\left(\mathrm{t}_{1 / 2}\right)$ were calculated.

\section{Results and discussion}

\section{Anthraquinones existed form of before and after oral gavage administration}

Most of the five anthraquinones are glycoside in Rhubarb, In order to determination the total anthraquinones we added $1.0 \mathrm{~mL}$ of $15 \%$ sulfuric acid in each samples and placed it in $70 \pm 2^{\circ} \mathrm{C}$ water bath for $30 \mathrm{~min}$ to hydrolysis conjunctive anthraquinones. The exits forms of anthraquinones in the extract solution of Rhubarb and WPY compounding formula solution before rabbits and rats oral gavage were shown in Figure 2 and that after oral were shown in Figure $2 \mathrm{~A}-2 \mathrm{~F}$. From the chromatogram we can see that anthraquinones can be determined under the separation conditions and there were no interference.

\section{Pharmacokinetics after oral gavage administration}

Plasma was gotten from ear vein after rabbits had oral gavage at 0 ,
$0.25,0.5,1,2,3,4,6,9,12,24$ hours. The concentration of rhein in rabbits plasma vs time curves were shown in Figure 3.
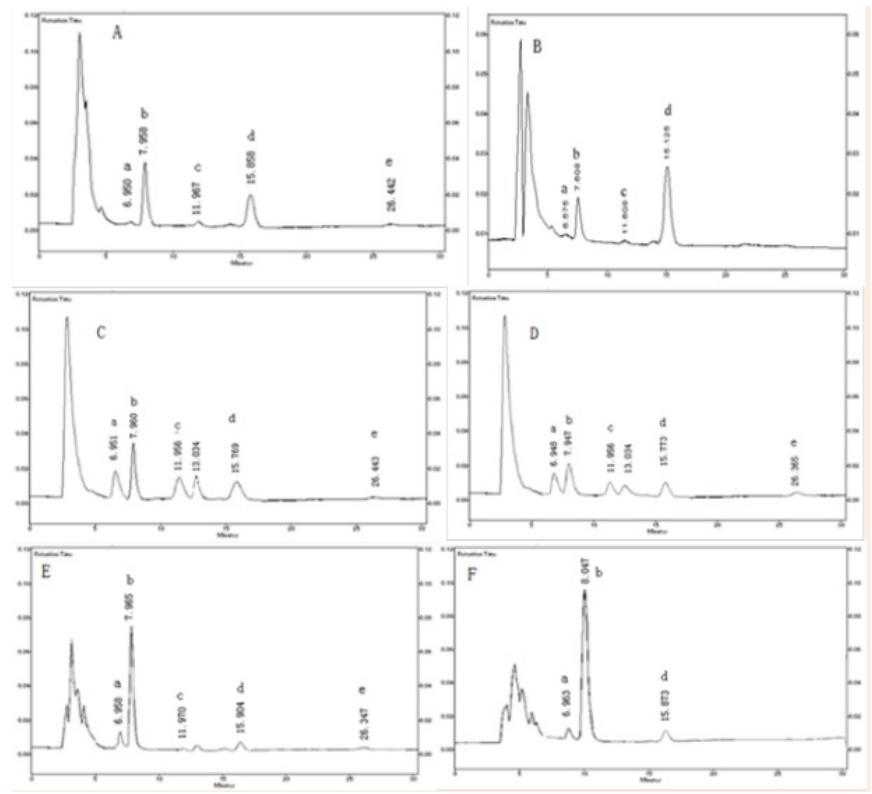

Figure 2A: A plasma sample taken from a rabbit after receiving an oral gavage of the extract solution of Rhubarb;

Figure 2B: A plasma sample taken from a rabbit after oral gavage of WPY, Figure 2C: The extract solution of Rhubarb before oral administration; Figure 2D: WPY before oral administration.

Figure 2E: A plasma sample taken from a rat after receiving an oral gavage of the extract solution of Rhubarb;

Figure 2F: A plasma sample taken from a rat after oral gavage of WPY. A: aloe-emodin emodin, B: rhein, C: emodin, D: chrysophanol, E. Physcion

Figure 2 The chromatography of Rhubarb anthraquinones in rabbits and rats plasma were achieved on a Hypersil $\mathrm{Cl} 8$ column $(10 \mathrm{~mm}, 4.6 \mathrm{~mm} \times 250 \mathrm{~mm}$ i.d.) The mobile phase consisted of methanol, acetonitrile and water (10:50:40, v/v, $\mathrm{pH} 2.8$ ) at a flow rate of $1.0 \mathrm{~mL} / \mathrm{min}$, and the detective wavelength was $225 \mathrm{~nm}$.

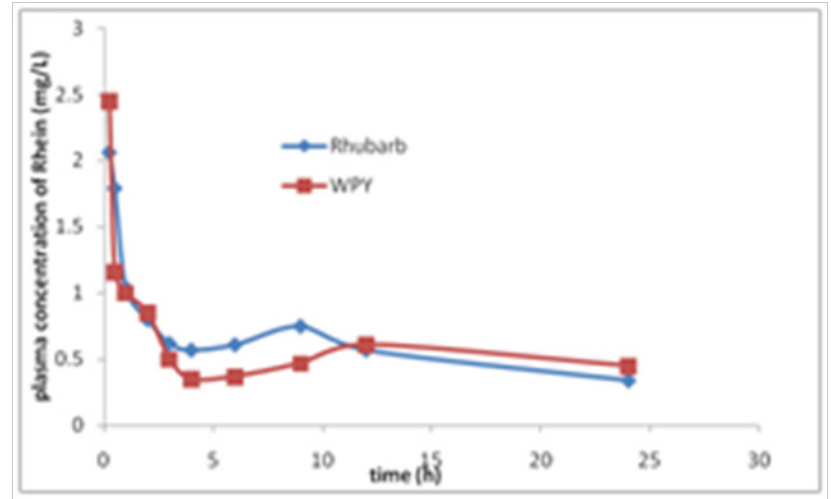

Figure 3 The curves of mean rhein concentration-time in rabbits plasma after oral gavage the extract solution of Rhubarb orWPY.

The pharmacokinetic parameters in rabbits after oral gavage of the extract solution of Rhubarb or compounding formula (WPY) were shown in Table 1. From Table 1 we can see that there were no significant differences $(\mathrm{p}<0.05)$ in the metabolism procedures of Rhubarb anthraquinones after rabbits had oral gavage different formulas. Plasma was obtained after rats had oral gavage of different formula at $5 \mathrm{~min}, 0.083,0.25,0.5,1,2,3,4,6,12$, 24hours. The concentration-time curves of rhein and total AQs in rat's plasma were shown in Figure 4. We can know that rhein increased and others decreased in rabbits and rats after oral gavage of different formulas 
containing Rhubarb. The elimination of total AQs was fit to a twocompartment model in rats. The Pharmacokinetic parameters of rhein and its comparison result were listed in Table $2 \& 3$ and Figure 5. The comparison results of pharmacokinetic parameters of rhein in rats and in rabbits plasma were shown in Figure 5. From Figure 5 and Table 4 we can see that there were no significant differences in the main pharmacokinetic parameters in rats after oral gavage of different formulas containing Rhubarb. That is, the metabolism procedures of Rhubarb anthraquinones in different formulas can be described with rhein. From Figure 5 we can see that there were no significant differences between rats and rabbits after oral gavage of different formulas which containing Rhubarb anthraquinones from the metabolism procedures. Pharmacokinetic study on singlerhubarb and compound formula of anthraquinone derivatives showed that the metabolism in rabbits and rats are consistent with twocompartment model; the pharmacokinetic parameters calculated with rhein can represent the behalf of Rhubarb Anthraquinones metabolism in the biological process. The results of biological samples study can extrapolated that Rhubarb AQs in the metabolic process in vivo may be carried out as Figures $6 \& 7$ shown. Combination of oxidation and metabolism. Oxidation is the 3-methyl (Chrysophanol) have been oxidized to hydroxymethyl (aloe-emodin) and carboxyl (rhein).
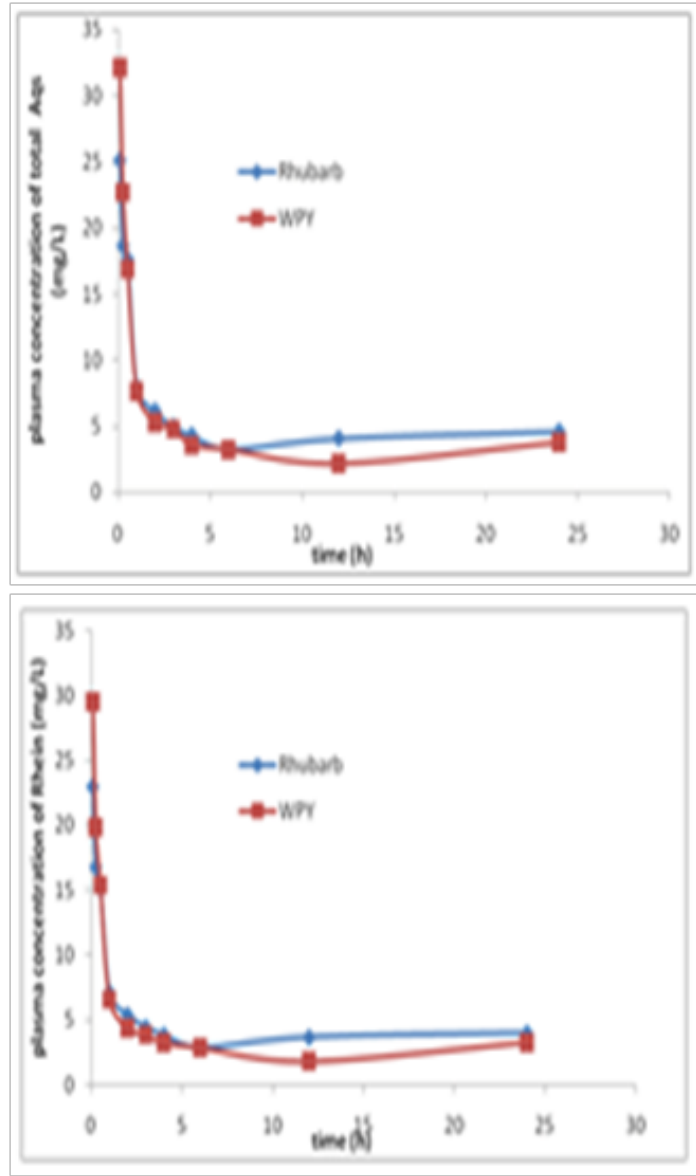

Figure 4 The curves of rhein or total AQs concentration-time in rats plasma after oral gavage of the extract solution of Rhubarb or WPY.

\section{Tissue distribution study on rats after oral gavage}

Tissue homogenates were obtained after rats had oral gavage different formula at $1,2,3,4,6,12$ hours. The concentrations of rhein in different tissues were obtained by HPLC and the data were shown in Table 5. From Table 5, we can see that total AQs and rhein were distributed in kidney, liver, blood and heart progressively. The anthraquinones were mainly existed as rhein in vivo and were excreted by the kidneys. The studies of distributions of Rhubarb anthraquinones were performed on 30 healthy rats after oral gavage of two formulas respectively. The results showed that Rhubarb anthraquinones in rats were distributed in kidney, liver, blood, heart progressively. It confirmed that the anthraquinones were mainly existed in rhein in vivo and excreted by kidney. The metabolic pathway of emodin may be described as Figure 7 shown. The metabolic processes can explain why the biological sample with a high concentration of rhein, and that of aloe-emodin and chrysophanol with low even do not detected.

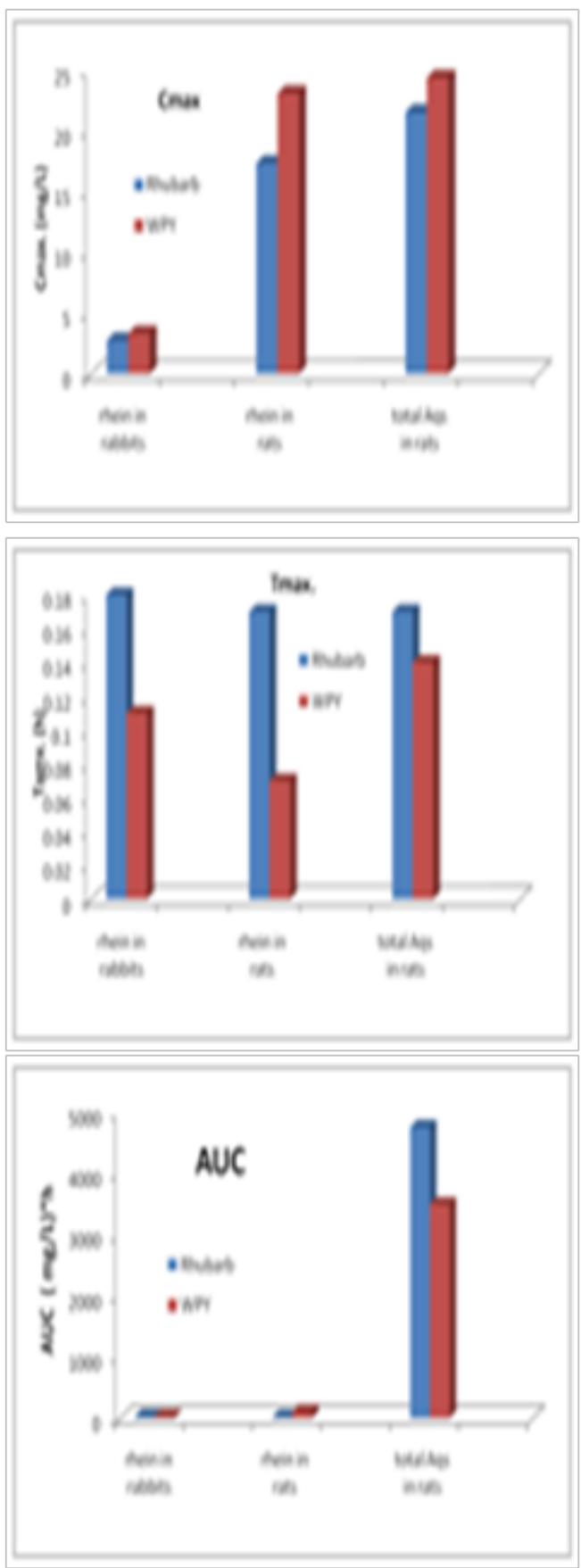

Figure 5 The comparison of the main pharmacokinetic parameters in rats and rabbits. 
Table I The pharmacokinetic parameters in rabbits after oral gavage of the extract solution of Rhubarb and WPY respectively

\begin{tabular}{|c|c|c|}
\hline $\begin{array}{l}\text { Pharmacokinetic parameters } \\
\text { compartment model }\end{array}$ & $\begin{array}{l}\text { Extract solution of rhubarb } \\
\text { two compartment }\end{array}$ & $\begin{array}{l}\text { WPY } \\
\text { two compartment }\end{array}$ \\
\hline Weighted Coefficient & I & I \\
\hline $\mathrm{A}(\mathrm{mg} / \mathrm{L})$ & $4 .|728 \pm 3.388|$ & $6.4958 \pm 4.0837$ \\
\hline$\alpha(1 / \eta \rho)$ & $2.4617 \pm 1.0525$ & $4.6488 \pm 4.2997$ \\
\hline$B(\mathrm{mg} / \mathrm{L})$ & $0.733 I \pm 2.2870$ & $0.6419 \pm 0.1647$ \\
\hline$\beta(1 / \eta \rho)$ & $0.0247 \pm 0.0782$ & $0.0250 \pm 0.0272$ \\
\hline $\mathrm{Ka}(\mathrm{I} / \mathrm{hr})$ & $6.5799 \pm 7.2936$ & $|3.4752 \pm 8.608|$ \\
\hline $\mathrm{V} / \mathrm{F}(\mathrm{c})(10 \mathrm{ml} / \mathrm{kg}) /(\mathrm{mg} / \mathrm{L})$ & $2.9922 \pm 4.0194$ & $2.0427 \pm 2.4699$ \\
\hline $\mathrm{t}_{1 / 2(\alpha)}(\mathrm{hr})$ & $0.28 I 6 \pm 1.3778$ & $0.149 \mid \pm 0.4757$ \\
\hline$T_{1 / 2(\alpha)}(\mathrm{hr})$ & $28.1055 \pm 16.2102$ & $27.7543 \pm 22.80 \mathrm{II}$ \\
\hline $\mathrm{t}_{\mathrm{I} / 2(\mathrm{ka})}(\mathrm{hr})$ & $0.1053 \pm 0.2860$ & $0.0514 \pm 0.0210$ \\
\hline $\left.\mathrm{K}_{21}^{\mathrm{in}(\mathrm{Ka} a} \mathrm{I} / \mathrm{hr}\right)$ & $0.5573 \pm 0.2609$ & $0.630 I \pm 0.2036$ \\
\hline $\mathrm{K}_{10}^{21}(\mathrm{I} / \mathrm{hr})$ & $0.1089 \pm 0.0520$ & $0.1843 \pm 0.1670$ \\
\hline $\mathrm{K}_{12}(\mathrm{I} / \mathrm{hr})$ & $1.8202 \pm 0.8233$ & $3.8594 \pm 4.3104$ \\
\hline AỦC $(\mathrm{mg} / \mathrm{ml}) * \mathrm{hr}$ & $30.6755 \pm 4.5517$ & $26.5689 \pm 8.6120$ \\
\hline $\mathrm{CL}_{(\mathrm{S})}(\mathrm{Iml} / \mathrm{l} / 00 \mathrm{~g}) / \mathrm{hr} /(\mathrm{mg} / \mathrm{L})$ & $0.3260 \pm 0.0437$ & $0.3764 \pm 0.5739$ \\
\hline $\mathrm{T}$ (peak) (hr) & $0.2800 \pm 3.1190$ & $0.1275 \pm 0.0232$ \\
\hline $\mathrm{Cmax}(\mathrm{mg} / \mathrm{L})$ & $2.0453 \pm 1.2900$ & $2.9512 \pm 1.7254$ \\
\hline
\end{tabular}

Table 2 Pharmacokinetic parameters with rhein or total AQs in rats after oral gavage of the extract solution of rhubarb andWPY respectively

\begin{tabular}{|c|c|c|c|c|}
\hline \multirow{2}{*}{$\begin{array}{l}\text { Pharmacokinetic } \\
\text { parameters }\end{array}$} & \multicolumn{2}{|c|}{ Extract solution of rhubarb } & \multicolumn{2}{|l|}{ WPY } \\
\hline & rhein & Total of AQs & rhein & Total of AQs \\
\hline Compartment Model & \multicolumn{4}{|l|}{ Two compartment } \\
\hline Weighted Coefficient & \multicolumn{4}{|l|}{$1 / C 2$} \\
\hline$A(m g / L)$ & $22.5419 \pm 20.8715$ & $22.1741 \pm 10.3235$ & $28.8972 \pm 13.7067$ & $39.5559 \pm 6.6164$ \\
\hline$\alpha(1 / \eta \rho)$ & $1.4575 \pm 0.9118$ & $|.32| 4 \pm 0.7375$ & $1.9421 \pm 0.3740$ & $2.3534 \pm 0.5 \mathrm{II} I$ \\
\hline$B(\mathrm{mg} / \mathrm{L})$ & $3.1455 \pm 0.4490$ & $3.7652 \pm 1.5683$ & $3.2091 \pm 1.2954$ & $4.1697 \pm 0.8693$ \\
\hline$\beta(1 / \eta \rho)$ & $-0.0119 \pm 0.0142$ & $-0.0082 \pm 0.0407$ & $0.0192 \pm 0.0336$ & $0.028 I \pm 0.007 \mid$ \\
\hline \multirow{3}{*}{$\begin{array}{l}\mathrm{Ka}(\mathrm{I} / \mathrm{hr}) \\
\mathrm{V} / \mathrm{F}_{(\mathrm{c})}(\mathrm{Iml} / \mathrm{I00g}) / \\
(\mathrm{mg} / \mathrm{L}) \\
\mathrm{t}_{\mathrm{I} / 2(\mathrm{a})}(\mathrm{hr})\end{array}$} & $18.6264 \pm 39.2112$ & $43.8505 \pm 1.9578$ & $44.0966 \pm 89.1147$ & $19.3712 \pm 38.2309$ \\
\hline & $0.0418 \pm 0.0134$ & $0.0396 \pm 0.0222$ & $0.0324 \pm 0.0377$ & $0.0257 \pm 0.0062$ \\
\hline & $0.4756 \pm 0.3074$ & $0.5246 \pm 1.1632$ & $0.3569 \pm 0.1153$ & $0.2945 \pm 0.1140$ \\
\hline $\mathrm{t}_{\mathrm{I} / 2(\mathrm{~b})}(\mathrm{hr})$ & $-58.1627 \pm 76.5560$ & $-84.77| \pm| 0.08 \mid$ & $36.0917 \pm 29.4595$ & $24.63| \pm| 221.592$ \\
\hline $\mathrm{t}_{1 / 2(\mathrm{ka})}(\mathrm{hr})$ & $0.0372 \pm 0.0635$ & $0.0158 \pm 0.0182$ & $0.0157 \pm 0.0131$ & $0.0358 \pm 0.0079$ \\
\hline $\mathrm{K}_{21}(\mathrm{I} / \mathrm{hr})$ & $0 .|8| 4 \pm 0.067 \mid$ & $0.1899 \pm 0.1395$ & $0.2193 \pm 0.0586$ & $0.2769 \pm 0.0170$ \\
\hline \multirow{2}{*}{$\begin{array}{l}\mathrm{K}_{10}(\mathrm{I} / \mathrm{hr}) \\
\mathrm{K}^{2}<>\text { sub }>12\end{array}$} & $-0.0958 \pm 0.1280$ & $-0.0569 \pm 0.4931$ & $0.1701 \pm 0.3426$ & $0.239 I \pm 0.1 \mid 46$ \\
\hline & $1.3599 \pm 0.9407$ & $1.180 I \pm 0.9179$ & $|.5720 \pm 0.037|$ & I.8654 \pm 0.5882 \\
\hline AUC ( $\mathrm{mg} / \mathrm{L})^{*} \mathrm{hr}$ & $26.0291 \pm 310.2810$ & $4753.93 \pm 5752.36$ & $|8| .248 \pm|| 5.889$ & $3494.16 \pm 6416.72$ \\
\hline $\mathrm{CL}_{(\mathrm{S})}(\mathrm{Iml} / \mathrm{l} 00 \mathrm{~g}) / \mathrm{hr} /(\mathrm{mg} / \mathrm{L})$ & $-0.0040 \pm 0.0053$ & $-0.0023 \pm 0.0303$ & $0.055 \pm 0.0256$ & $0.006 I \pm 0.0039$ \\
\hline $\mathrm{T}$ (peak) (hr) & $0.1583 \pm 0.1170$ & $0.1698 \pm 0.1083$ & $0.0746 \pm 0.05 \mathrm{II}$ & $0.1364 \pm 0.0300$ \\
\hline $\mathrm{Cmax}(\mathrm{mg} / \mathrm{L})$ & $19.7035 \pm 1.2258$ & $21.5728 \pm 2.1430$ & $27.0116 \pm 13.6160$ & $24.3986 \pm 5.3003$ \\
\hline
\end{tabular}

Table 3 The results of paired samples test of pharmacokinetic parameters in rabbits (rhein)

\begin{tabular}{|c|c|c|c|c|c|c|}
\hline No. & $\begin{array}{l}\text { AUC } \\
\text { Extract Solution of Rhubarb }\end{array}$ & WPY & $\begin{array}{l}T_{\max .} \\
\text { Extract Solution of Rhubarb }\end{array}$ & WPY & $\begin{array}{l}C_{\max .} \\
\text { Extract Solution of Rhubarb }\end{array}$ & WPY \\
\hline $\bar{x}$ & 33.16 & 34.4 & 0.18 & 0.11 & 2.78 & 3.34 \\
\hline SD & 4.55 & 25.29 & 0.15 & 0.02 & 1.29 & 1.73 \\
\hline 2-tailed t-test & $\mathrm{t}=17.86$ & $\mathrm{t}=3.33$ & $t=3.07$ & $\mathrm{t}=3.61$ & $\mathrm{t}=5.29$ & $\mathrm{~T}=4.74$ \\
\hline t-test point value & $\mathrm{t}_{0.05}=4.303 \mathrm{t}_{0.001}=31.599$ & & & & & \\
\hline Paired t-test & 0.144 & 0.149 & \multicolumn{4}{|c|}{1.525} \\
\hline Paired t-test $P$ value & 0.895 & 0.294 & \multicolumn{4}{|c|}{0.405} \\
\hline
\end{tabular}

Table 4 The results of paired samples test of pharmacokinetic parameters in rats (total AQs)

\begin{tabular}{|c|c|c|c|c|c|c|}
\hline \multirow{2}{*}{ No. } & \multicolumn{2}{|l|}{ AUC } & & \\
\hline & Extract Solution of Rhubarb & WPY & Extract Solution of Rhubarb & WPY & Extract Solution of Rhubarb & WPY \\
\hline $\bar{x}$ & 4753.93 & 3494.16 & 0.17 & 0.14 & 21.57 & 24.40 \\
\hline SD & 5752.36 & 26.07 & 0.11 & 0.03 & 2.14 & 0.12 \\
\hline 2-tailed t-test & $\mathrm{t}=2.02$ & $\mathrm{t}=-\mathrm{I} .33$ & $\mathrm{t}=3.85$ & $\mathrm{t}=\mathrm{I} \mid .00$ & $\mathrm{t}=24.68$ & $\mathrm{t}=484.13$ \\
\hline t-test point value & $\mathrm{t}_{0.05}=4.303 \mathrm{t}_{0.001}=31.599$ & & & & & \\
\hline Paired t-test & 1.784 & 1.025 & & 3.08 & & \\
\hline Paired t-test $P$ value & 0.172 & 0.381 & & 0.05 & & \\
\hline
\end{tabular}

Citation: Cui T, Zhou QX, Zhang D, et al. Investigation the distributions and pharmacokinetics of five Rhubarb anthraquinones in rabbits and rats. J Anal Pharm Res. 2016;3(2):I I-I2. DOI: I0.15406/japlr.2016.03.00048 
Table 5 The data of rhein concentration in 30 rats after oral gavage of the extract solution of Rhubarb and WPY respectively

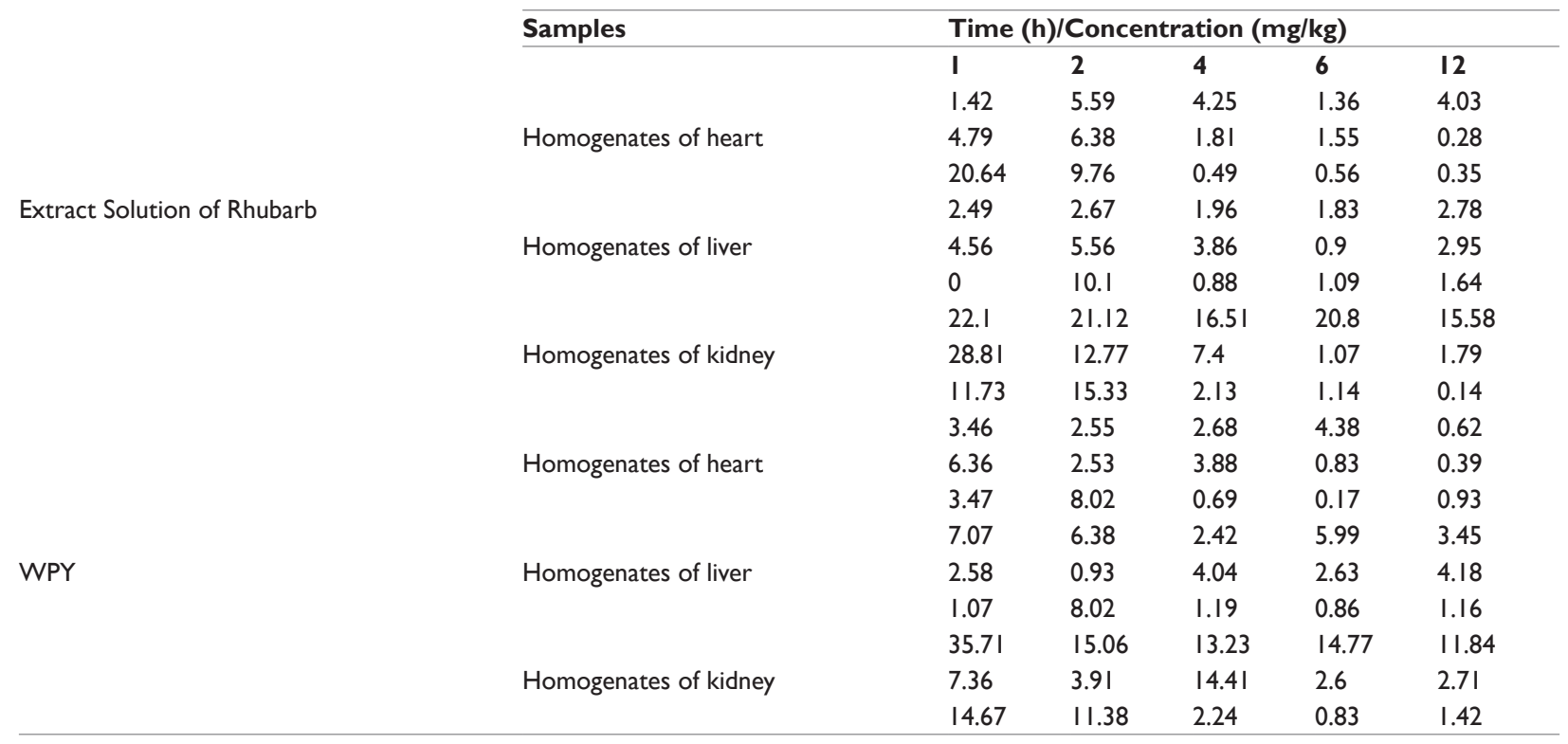

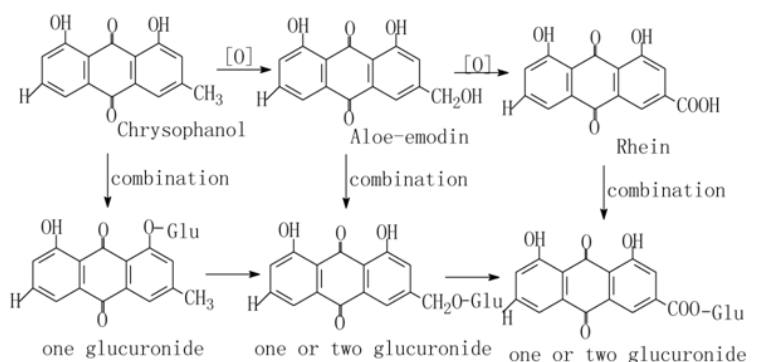

Figure 6 The metabolic pathway of chryophanol in vivo after rats oral gavage of different preparation containing Rhubarb.

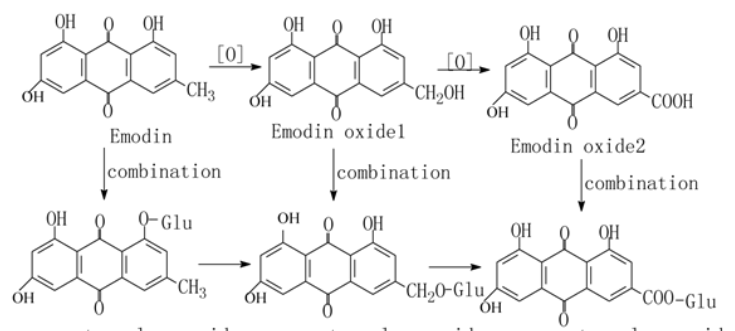

one or two glucuronide one or two glucuronide one or two glucuronide

Figure 7 The metabolic pathway of emodin in vivo after rats oral gavage of different preparation containing Rhubarb.

In view of the complexity of Chinese herbal compound, a comprehensive picture of what all of its chemical constituents of the absorption, distribution, metabolism and excretion of the law is very difficult. To clarify the effectiveness of components can be detected and their dynamic changes in vivo, the efficacy of Chinese medicine composed of clear material basis, Compatibility of the law reform and clinical forms are useful medication.

\section{Conclusion}

The results of our studies could provide references for investigation of pharmacokinetics and distributions and of relations between pharmacokinetics, distributions and clinical efficacy of Rhubarb anthraquinones in human body, and provide a new thinking method for exploit and application of the traditional chinese medicine preparations. And to the preparations containing Rhubarb, rhein could be used as a probe for pharmacokinetic study of anthraquinones in vivo (Figure 8).

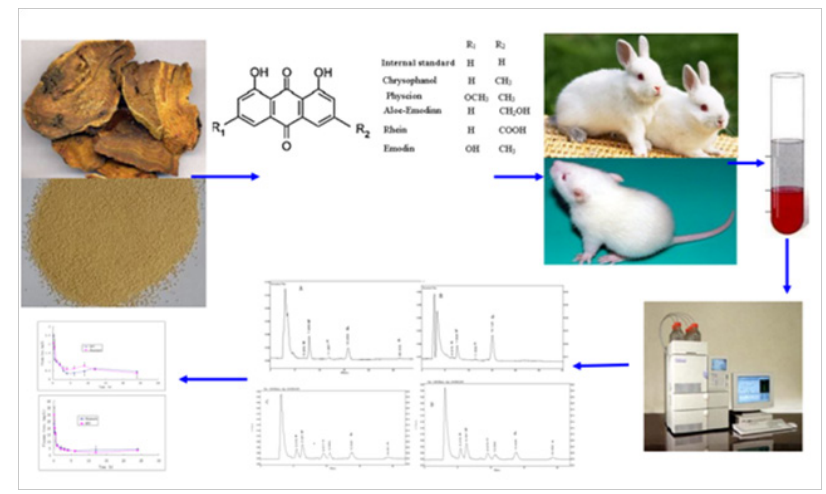

Figure 8 Graphical Abstract.

\section{Acknowledgments}

Thanks are due to Professor Jia Y.R. for Rhubarb of Cangdu Rheum PalmatumL and WPY provided.

\section{Conflicts of interest}

The authors declare no conflict of interest.

\section{Funding}

None.

\section{References}

1. The State Pharmacopoeia Commission of P. R. China. People's Medical Publishing House:Beijing, China; 2010. p. 296-297.

2. General Rules for Crude Drugs. 15th ed. Japanese Pharmacopoeia, Tokyo; 2006. p. 1344-1345.

3. European Directorate for the Quality of Medicines. 4th ed. European Pharmacopoeia, Strasbourg; 2001. p.1858-1859. 
4. WHO. Monographs on Selected Medicinal Plants. World Health Organization, Geneva; 1991. p. 231-240.

5. Huang KC. The Pharmacology of Chinese Herbs. CRC Press; 1993. 544 p.

6. Shang XY, Yuan ZB. Determination of six components in Rhubarb by cyclodextrin- modified micellar electrokinetic chromatography using a mixed micellar system of sodium cholate and sodium taurocholate. Analytica Chimica Acta. 2002;456(2):183-188.

7. Kuo $\mathrm{CH}$, Sun SW. Analysis of nine rhubarb anthraquinones and bianthrones by micellar electrokinetic chromatography using experimental design. Analytica Chimica Acta. 2003;482(1):47-58.

8. Shang XY, Yuan ZB. Determination of Active Components in Rhubarb by Cyclodextrin-modified Capillary Zone Electrophoresis. Sensors. 2001;1(7):229-235.

9. Fernand VE, Dinh DT, Washington SJ, et al. Determination of pharmacologically active compounds in root extracts of Cassia alata $L$. by use of high performance liquid chromatography. Talanta. 2008;74(4):896-902.

10. Wang J, Li H, Jin C, et al. Development and validation of a UPLC method for quality control of rhubarb-based medicine:Fast simultaneous determination of five anthraquinone derivatives. J Pharm Biomed Anal. 2008;47(4-5):765-770.

11. Qu H, Ma Y, Yu K, et al. Simultaneous determination of eight active components in Chinese medicine 'YIQING' capsule using high-performance liquid chromatography. $J$ Pharm Biomed Anal. 2007;43(1):66-72.
12. He D, Chen B, Tian Q, et al. Simultaneous determination of five anthraquinones in medicinal plants and pharmaceutical preparations by HPLC with fluorescence detection. J Pharm Biomed Anal. 2009;49(4):1123-1127.

13. Chunxia L, Hongxin W, Wenping L, et al. Ionic liquid-based ultrasonic/microwave-assisted extraction combined with UPLC for the determination of anthraquinones in rhubarb. Chromatographia. 2011;74(1):139-144.

14. Zhang HF1, Shi YP. Temperature-assisted ionic liquid dispersive liquid-liquid microextraction combined with high performance liquid chromatography for the determination of anthraquinones in Radix et Rhizoma Rhei samples. Talanta. 2010;82(3):1010-1016.

15. Koyama J, Morita I, Kobayashi N. Simultaneous determination of anthraquinones in rhubarb by high-performance liquid chromatography and capillary electrophoresis. J Chromatogr A. 2007;1145(1-2):183189.

16. Zhang LS, Hu S, Chen X, et al. A new ionic liquid-water-organic solvent three phase microextraction for simultaneous preconcentration flavonoids and anthraquinones from traditional Chinese prescription. $J$ Pharm Biomed Anal. 2013;86:36-39.

17. Tian J, Chen X, Bai XH. Comparison of dispersive liquid-liquid microextraction based on organic solvent and ionic liquid combined with high performance liquid chromatography for the analysis of emodin and its metabolites in urine samples. J Sep Sci. 2012;35(1):145-152.

18. Mandrioli R, Mercolini L, Ferranti A, et al. Determination of aloe emodin in Aloe vera extracts and commercial formulations by HPLC with tandem UV absorption and fluorescence detection. Food Chemistry. 2011;126(1):387-393. 